\title{
Market Structure and Financial Stability: the Interaction between Profit-Oriented and Mutual Cooperative Banks in Italy
}

\author{
Adalgiso Amendola ${ }^{1} \cdot$ Cristian Barra $^{1}$ (D) Marinella Boccia ${ }^{1} \cdot$ Anna Papaccio $^{1}$
}

Received: 23 April 2020 / Revised: 9 June 2021 / Accepted: 14 June 2021 /

Published online: 27 July 2021

(C) The Author(s) 2021

\begin{abstract}
In this study, we analyze the relation between market structure and financial stability both theoretically and empirically by considering two types of agents: profit-oriented banks and mutual cooperative banks in the context of Italy. The main findings show that under the condition that mutual cooperative banks are not dominated by borrowers, there is an inverted U-shaped relation in which a less concentrated market structure increases stability for both types of banks but a more concentrated market structure reduces it.
\end{abstract}

Keywords Marketstructure $\cdot$ Financial stability $\cdot$ Profit-oriented banks $\cdot$ Mutual cooperative banks

JEL Classification $\mathrm{G} 21 \cdot \mathrm{G} 28 \cdot \mathrm{C} 14 \cdot \mathrm{D} 21$

\section{Introduction}

The 2008-2009 global financial crisis severely affected the world economy and triggered a lively debate on the stability of the financial system and the related regulation policies that could limit the contagion effect of such crises on the real economy. In recent years, a major

Cristian Barra

cbarra@unisa.it

Adalgiso Amendola

adamendola@unisa.it

Marinella Boccia

mboccia@unisa.it

Anna Papaccio

apapaccio@unisa.it

1 DISES-Department of Economics and Statistics, CELPE-Centre for Labour Economics and Economic Policy, University of Salerno, Via Giovanni Paolo II, 84084 Fisciano, SA, Italy 
source of worldwide concern has become the relation between the structure of the credit market and its financial stability. Both theoretical and empirical studies on credit markets have investigated the effects of concentration on banking stability (Allen and Gale, 2004; Boyd and De Nicoló, 2005; Beck et al., 2006b; Fu and Heffernan, 2009; Koutsomanoli-Filippaki et al., 2009; Fang et al., 2011). However, these studies offer ambiguous predictions.

Therefore, this study aims to contribute to the literature on the relation between market structure and financial stability, both from a theoretical and an empirical point of view, with a focus on the difference between mutual cooperative banks and profit-oriented banks in the context of Italy. In particular, we test whether an increase in concentration positively affects the stability of the financial system.

On the theoretical side, some models, such as Allen and Gale (2004), predict that an increase in competition will result in a higher risk of bank failure that indicates banks could invest high monopoly rents in safe assets. The so-called "concentration-stability view" argues that in concentrated banking systems, larger (monopolistic) banks can enhance profits and thus increase financial stability by providing higher "capital buffers" that protect them against external macroeconomic and liquidity shocks (Boyd et al., 2006).

However, some studies argue that lower concentration can bolster stability as it identifies, condenses, and uses dispersed or latent information that thus overcomes divided knowledge (Canvoy et al., 2001; see also Carletti and Hartmann 2003). Furthermore, others, like Boyd and De Nicoló (2005), find that lower concentration reduces the interest rate of a borrowing firm that leads the borrower to choose a safer project that in turn makes the bank more stable. Repullo et al.'s (2010) model predicts a nonlinear effect of concentration on bank risk: lower concentration first increases the risk-taking of banks and then reduces it.

On the empirical side, De Nicoló et al. (2004) provide evidence of increased risk profiles for the five largest conglomerate financial firms and of a higher level of potential systemic risk for more concentrated banking systems. Schaeck and Čihák (2007) and Schaeck et al. (2009) examine the effects of market competition and concentration on systemic stability for more than 2600 banks in the EU-10 plus Switzerland for the period from 1999 to 2004. They find no evidence of a trade-off between concentration and competition and banks' risk-taking.

Since the 2008-2009 financial crisis, studies have shown that mutual cooperative banks (stakeholder banks) play a stabilizing role in the banking system. In fact, Coco and Ferri (2010) argue that a lack of financial stability derives mostly from bank owners' incentives and the conflict between owners and depositors. Therefore, in mutual cooperative banks, where the owner-members are also depositors, this problem is less severe, and therefore they have fewer incentives to increase risk. Moreover, they find that the effect of the crisis has shown the sustainability of the stakeholder model with respect to the profit-orientated (shareholder) model of a financial intermediary. De Santis and Surico (2013) argue that mutual cooperative banks and savings banks protect their customers from monetary policy shocks and that mutual cooperative banks' lending is less procyclical than that of profit-orientated banks. Ayadi et al. (2010) argue that the economy is thus exposed to intertemporal risk because of a lack of reserves since profit-orientated banks are less likely to collect reserves for future losses than mutual cooperative banks. Olszak et al. (2017) use data from 27 EU countries from 1996 to 2011 to show that Western European mutual cooperative banks have less cyclical loan loss provisions (LLP) than their profit-orientated counterparts. A similar result is shown by Alessi, di Colli and Lopez (2014) who find that the LLPs of Italian mutual cooperative banks are less cyclical than those of Italian profit-orientated banks from 2006 to 2012 . 
Rajan (1994) identifies an incentive in the cooperative business model to undertake less risky investments; moreover, as shown by Hesse and Čihák (2007), mutual cooperatives banks have a lower income volatility that leads to a rise in z-scores and greater stability in this category of banks and in the financial system in which they operate. These settings are also confirmed by other authors (Ayadi et al., 2010; Stefancic, 2010; Groeneveld, 2011).

Cioli and Giannuozzi (2014) study the effect on the riskiness of the different banks' business models. They use the z-score as a proxy for financial stability and refer to financial statements of Italian mutual cooperative banks from 2006 to 2011 and compare the results with Italian profit-orientated banks.

The findings are in line with other studies performed in other countries and show that mutual cooperative banks have a greater degree of financial stability. In particular, they are better capitalized and invest less in derivatives. Therefore, these financial institutions can play a role in stabilizing a financial system during a financial crisis. However, there are also studies that adopt the opposite approach. For instance, Goodhart (2004) confirms the peculiarities of the cooperative credit union but shows that these institutions contribute to the instability of the financial system for two reasons: first, they push profit-orientated banks to turn to riskier assets to increase profit margins; second, they are also more affected by credit shocks because they are primarily focused on intermediation activities and have a low level of diversification in their assets.

To the best of our knowledge, very few studies have been aimed at verifying, both theoretically and empirically, the relation between market structure and financial stability by considering the differences between profit-oriented banks (PBs) and mutual cooperative banks (MBs).

Thus, we follow the structure-conduct-performance approach (Mason 1939; Bain 1956) to concentrate on the strategic interaction of banks and on the effect of a change in the number of competitors on their stability as a measure of concentration (and competition). In order to take into account, the polymorphism that still characterizes the banking systems in Europe (Ayadi et al., 2010), we consider banks' strategic interaction in a mixed oligopoly setting that accounts for the presence of two types of agents: profit-oriented banks (that we define as PBs) and mutual cooperative banks (that we define as MBs). The model adapts the Klein-Monti approach (Klein, 1971) of a monopolistic bank to a case of imperfect mixed Cournot strategic interaction between MBs and PBs in the lending market. Following Allen and Gale (2004) and Martinez-Miera and Repullo (2010), we include a form of credit risk, but unlike them, we assume that credit risk is dependent on the quality of the information gathered by banks. We do so to capture the effect of the competition between different groups of agents and within each group on bank performance.

We find that when MBs are not dominated by borrowers, a decrease in concentration in a heterogeneous financial market increases stability. On the other hand, when MBs are dominated by borrowers, a decrease in concentration has an ambiguous effect on the stability of the financial system.

To empirically investigate the relation between concentration and financial stability, we use an Italian banking data set that covers the period from 1994 to 2015. This dataset makes it possible to consider PBs and MBs separately. In the empirical analysis, we use a parametric approach by applying the recent model by Kumbhakar et al. (2014). Specifically, we assess the effects of market structure by using the Herfindahl-Hirschman indicator and market share on the inefficiency of stability. ${ }^{1}$ The empirical evidence identifies an inverted U-shaped relation

\footnotetext{
${ }^{1}$ We assume that two types of banks in our sample have the same lending technologies. We then use the SCP (structure-conduct-performance) approach in order to construct market structure indicators (such as the HHI). In other words, MBs can have the same opportunities in terms of competition to grant loans to customers as nonMBs.
} 
between market concentration and the stability of banks in which a lower concentration increases stability, but a higher concentration reduces stability. ${ }^{2}$

This study is organized as follows: The next Section briefly surveys the literature on the relation between market structure and financial stability. In Section 3, we present a mixed oligopoly model of bank strategic interaction. Section 4 presents the empirical strategy and data, and some stylized facts are discussed. In Section 5, we illustrate and discuss the findings of the theoretical model. We describe the results of the empirical analysis in Section 6. Section 7 concludes and provides suggestions in terms of policy decisions.

\section{Related Studies: Market Structure and Financial Stability}

Economic theory offers differing hypotheses about the relation between market structure and the stability of the banking system. Studies on the relation between market concentration and financial stability generally find that in more concentrated and collusive credit markets, larger (monopolistic) banks can have higher profit premiums that then provide higher "capital buffers" and reduce the incentives to take risks (Hellman et al., 2000; Boyd et al., 2006). Nevertheless, by referring to the "too big to fail" hypothesis, other studies show that more concentrated markets with the presence of a few relatively large banks could have a destabilizing effect on financial systems. Indeed, when concentration is particularly strong, some banks have so much weight and market power that their failure would result in the collapse of the entire financial system. Therefore, anticipating the unwillingness of the regulator to let them fail in the event of insolvency problems, they might have an incentive to increase their risk exposure (Hughes and Mester, 1998). Thus, the implicit or explicit assurance of rescue in the case of bankruptcy encourages risk-taking by banks, which will ultimately increase systemic risk (Mishkin, 1999).

Some theoretical contributions analyze the effects of competition on banks' vulnerability to systemic risk on the liability side. For instance, Smith (1984) finds that competition for deposits reduces banks' stability. Other contributions focus on the competition for loans but also consider liquidity shocks on the liability side by using a differentiated oligopoly for the loan market. These analyses show that the effect of competition increases banks' stability (Carletti and Hartmann 2003). Some authors extended the Klein-Monti model to show that increased competition induces banks to choose riskier portfolio strategies, and they find a negative relation between the level of a bank's credit risk and that of its market share through deposits (Dermine, 1986; Broecker, 1990; Besanko and Thakor, 1993). Conversely, some contributions find a positive relation between competition and bank stability (Stiglitz and Weiss, 1981; Boyd and De Nicoló, 2005).

Exploring the traditional "concentration-stability" view, Hellmann et al. (2000) show that a reduction in concentration in the deposits market lowers the profitability of banks. Allen and Gale (2004) also affirm that the increased risk might be due to increased exposure to contagion in less concentrated markets. Recent research by Martinez-Miera and Repullo (2010) allows for a nonlinear relation between measures of bank risk and market structure. When banks charge lower rates, their borrowers have an incentive to choose safer investments, so they will

\footnotetext{
2 This is equal to say that there is a $U$ shaped relationship between the concentration and the inefficiency of stability and that for a lower level of concentration the inefficiency of stability decreases, but for higher level of concentration the inefficiency of stability increases.
} 
in turn be safer. However, this argument does not account for the fact that lower rates also reduce the banks' revenues from performing loans. They show that when this effect is accounted for, a U-shaped relation between competition and stability arises.

Studies have also empirically explored the relation between the structure of the credit market and the stability of the financial system but with ambiguous results. Some studies find a negative relation between market concentration and financial stability. De Nicoló and Loukoianova (2007) consider the z-score index and find that it decreases with the market concentration of banks as measured by the Herfindahl-Hirschman index (or HHI). This finding indicates that the risk of bank failure increases in more concentrated markets.

Similarly, using panel data from across the EU-25 for the period from 1997 to 2005, Uhde and Heimeshoff (2009) provide empirical evidence that the national concentration of the banking market has a negative effect on European banks' financial soundness. They measure this concentration with the $z$-score while controlling for macroeconomic, bank-specific, regulatory, and institutional factors. Furthermore, their analysis indicates that Eastern European banking markets have a lower level of competitive pressure, fewer diversification opportunities, and a higher fraction of government-owned banks. These factors mean they are more prone to financial instability, while capital regulations have supported financial stability across the entire European Union. Later, based on Italian local data, Barra and Zotti (2019) find that the higher market concentration of MBs affects systemic stability by reducing the z-scores of PBs. This finding supports the hypothesis that the presence of non-profit-maximizing entities can pull down the stability of other financial institutions.

Some other studies that analyze the link between low concentration and instability find the same nexus. For instance, Schaeck et al. (2009) find that the less concentrated banking systems (measured using the Panzar and Rosse H-statistic) have lower likelihoods of bank failure and take a longer time to reach a crisis and hence are more stable than monopolistic systems. Conversely, empirical research also offers evidence of a positive relation between concentration and stability in credit markets. Empirical findings show that more concentrated markets have a positive effect on the stability of the banking system by generating a lower level of failure among banks. On the other hand, Keeley (1990) shows that a reduction in concentration have caused bank charter values to decline that in turn, has caused banks to increase default risk through increases in asset risk and reductions in capital. Also inconsistent with the concentration-fragility views are the results of Beck et al. (2006a). Their analyses indicate that national bank concentration reduces the likelihood that a country will suffer a systemic banking crisis. The results also hold when controlling for a wide array of macroeconomic, regulatory, and institutional factors, when using different definitions of crisis and concentration, and when examining different subsamples of countries. But, while their findings hold for the subsample of developing countries, they cannot confirm or reject these results when restricting the sample to high-income countries - not surprising given the limited number of countries and crises. Further, other empirical cross-country analyses on the relation between the concentration and instability of the banking system have ambiguous results. For instance, Berger et al. (2009) use three proxies for financial stability: a measure of overall bank risk, a measure of loan risk, and the capital ratio as an indicator of effort to control overall bank risk. $^{3}$ They also separately consider and compute several alternative measures of bank competition, such as the Lerner index. The results show that - in line with the traditional

\footnotetext{
$\overline{3}$ According to Martin-Oliver et al. (2013), equity capital protects against losses and better contributes to financial stability.
} 
"competition-fragility" view - banks with a higher degree of market power also have less overall exposure to risk. The data also provide some support for one element of the "concentration-fragility" view - that market share increases loan portfolio risk. They show that this risk may be offset in part by higher ratios of equity capital. After controlling for macroeconomic conditions and bank characteristics, they use standard measures of market concentration and find support for a nonlinear relation between bank competition and risk-taking in both the loan and deposit markets. When direct measures of market share, such as Lerner indices, are used, the empirical results are more supportive of the original franchise value hypothesis, ${ }^{4}$ but only in the loan market. Overall, the results highlight the empirical relevance of the Martinez-Miera and Repullo (MMR, 2010) model, although further analysis across other banking markets is needed.

To conclude, an important part of the literature, focusing on thrift institutions mutually owned by depositors (Maksimovic and Unal 1993, Unal 1997) argue that a conversion from a mutual to a stock association allows firms to raise equity capital, reducing the probability of insolvency by providing a cushion against failure. Moreover, analyzing risk management activities when multiple risks are bundled within a firm's assets or liabilities, Schrand and Unal (1998) show that mutual thrifts which convert to stock institutions reduce interest-rate risk and this leads to a slower growth in credit risk. Masulis (1987), focusing on the economic causes and consequences of the organizational change by mutual savings and loan associations, when decide to convert to stock charter, finds that the conversion yields organizational efficiency gains. In particular, the organizational change is associated with an increase of equity capital and a decreased risk of insolvency. What more, results show that mutual institutions are more likely to convert to stock associations in markets that exhibit greater competition and growth.

\section{A Mixed Oligopoly Model of Bank Strategic Interaction}

In this Section, we theoretically investigate the relation between the structure and instability of the credit (local) market when different types of banks operate in that market. The market structure is measured by the number of competitors, as a proxy for the (local) market concentration degree. To do so we extend the Klein-Monti model (Klein 1971) of a monopolistic bank to a case of mixed Cournot interaction between two types of agents in the market MBs and PBs. To simplify our analysis, we assume that there are M identical PBs and $\mathrm{N}$ identical MBs in the market that respectively supply loans $L_{j}$ and $L_{i}$ (with $i=1, \ldots, N$ and $j=1$, $\ldots, M)$. Following Repullo et al. (2008) and Boyd and De Nicoló (2005), we assume that they have fully insured deposits, have no capital, and invest in a portfolio of entrepreneurial loans. The supply of deposits is perfectly elastic at an interest rate that is normalized to zero, and there are no intermediation costs.

The PBs maximize a profit function that competes with the other PBs and MBs in the loan market. Following Allen and Gale (2004), we assume that a fraction $\rho$ of a bank's loans defaults in which case it loses the interest and a fraction $\lambda$ of the total amount. On the other hand, the bank gets $L_{j}(1+r)$ from the fraction $(1-\rho)$ of the loans that do not default and recovers $L_{j}(1-\lambda)$ from the fraction $\rho$ of defaulted loans and has to pay back $L_{j}$ to the depositors.

\footnotetext{
${ }^{4}$ Under the franchise-value hypothesis, more efficient firms may choose lower leverage to protect the economic rents derived from higher efficiency and the possibility of liquidation (Margaritis and Psillaki, 2010).
} 
The PBs $j$ pay-off is thus represented by the following profit function:

$$
\pi_{j}(\bar{L})=L_{j}(1+r(\bar{L}))(1-\rho)+L_{j}(1-\lambda) \rho-L_{j}
$$

where $r(\bar{L})=a-\bar{L}$ (with $\bar{L}=\sum_{i=1}^{N} L_{i}+\sum_{j=1}^{M} L_{j}$ ) that represents the inverse demand for loans in the market.

A number of researchers have argued that PBs (often larger than local banks) are less capable of processing and transmitting the relational (soft) information through their hierarchical structures that is typical of MBs (Boot, 2000; Ghatak, 2000; Stein, 2002; Elyasiani and Goldberg 2004). As a consequence, PBs gather a kind of information (hard) that can be separated from its actual use, since it is standardized and based on data collection. On the other hand, MBs hold an information advantage (soft information) given by their proximity to customers. For sake of simplicity, we do not make distinctions between the kind of information the two types of banks can achieve.

The term $\rho$ can be thought of as an inverse measure of information accuracy through its specific effect on credit risk by assuming that the PB fails when $\pi_{j}(\bar{L})<0 .^{5}$ This circumstance happens if

$$
\rho>\frac{r}{r+\lambda} \equiv \widehat{\rho}
$$

We can consider $\widehat{\rho}$ as the maximum level of nonperforming loans that a PB is able to accept over which it is in a state of failure. In other words, if the fraction of nonperforming loans $\rho$ is greater than the default rate $\widehat{\rho}$, then the bank is defaulting.

The MBs have a mutualistic feature and a regional limit to expansion. The main peculiarity that distinguishes MBs from PBs depends on their bottom-line objectives and the extent to which profit maximization is the central focus of their business models. Specifically, MBs are dual-objective institutions (Groeneveld and de Vries, 2009), since these financial institutions need to generate profits in order to survive and expand, but profit is not the sole or even primary bottom-line objective. Their primary concern is to balance the different interests of the various stakeholders in them; this means that a $\mathrm{MB}$ will not pursue profit maximization to the same degree, or with the same intensity, as will a PB (Llewellyn, 2005). Moreover, ownership is dispersed (along the "one head-one vote" principle), and borrowers are typically members of the cooperative.

The MBs' primary mission is to promote economic benefits for their members, who are also their customers; for this reason, the specification of the objective function should focus on the value of the banks' participation to the members. Like Emmons and Schmid (2002), we describe the MBs' objective function as the weighted sum of members' surplus $S\left(L_{i}\right)$ and the

\footnotetext{
5 The collection of non-public knowledge about firms and customers confers on banks an informational advantage over other financial operators (Cornée, 2014). Information collected can be distinguished into two types: hard and soft information. Hard information is quantitative and can easily be collected, stored and transmitted. The collection method need not be personal, which lowers the cost but limits what types of data can be collected. Moreover, the collection of the information can be separate from the use of the information (Liberti and Petersen 2018). Soft information refers to implicit (or idiosyncratic) knowledge that takes the form of unpublished, informal aspects of the customer. The context in which the information is collected and the collectors of the information are part of the information itself and cannot be separated (Liberti and Petersen 2018).
} 
banks' profits. We consider only the fraction of members who are also borrowers ${ }^{6}$ from the bank $(\theta)$ since we focus on credit risk.

The MBs' maximize the following utility function:

$$
\begin{gathered}
U_{i}(\bar{L})=\alpha \theta S\left(L_{i}\right)+(1-\alpha) \pi_{i}(\bar{L}) \\
U_{i}(\bar{L})=\alpha \theta S\left(L_{i}\right)+(1-\alpha) L_{i}(r-\rho(r+\lambda))
\end{gathered}
$$

The first component of MBs' objective function is to increase the level of loans supplied to members. Since the second component of (Eq. 4) is to decrease the level of loans, the maximization problem of MBs is the balance of the different but interconnected interests of members and its survival.

$$
\begin{aligned}
& \text { (Furthermore, } U_{L_{i}}^{\prime}>0 \text { if } 0<\rho<\frac{r}{r+\lambda} \quad \text { or } \quad \frac{r}{r+\lambda}<\rho<1 \text { and } S^{\prime} \\
& >\frac{(1-\alpha)(\rho(r+\lambda)-r)}{\alpha \theta}
\end{aligned}
$$

As Hesse and Čihák (2007) point out, MBs' lower volatility in their returns derive directly from their ability to use their customer surplus to mitigate low profit periods. Moreover, a number of empirical studies conclude that, since stock-owned banks have higher risk-taking incentives, mutual associations have lower risk than stock institutions (Verbrugge and Goldstein, 1981; O'Hara, 1981; Cordell et al. 1993; Lamm-Tennant and Starks, 1993; Esty, 1997; Schrand and Unal, 1998).

In this regard, we assume that an MB fails when $U_{i}(\bar{L})<0$. This event happens if

$$
\rho>\frac{r}{r+\lambda}+\frac{\alpha}{(1-\alpha)} \frac{\theta S\left(L_{i}\right)}{L_{i}} \frac{1}{(r+\lambda)}
$$

Since $\widehat{\rho}=\frac{r}{r+\lambda}$, we can manipulate condition (5):

$$
\begin{gathered}
\left.\rho>\widehat{\rho}+\frac{\alpha}{(1-\alpha)} \frac{\theta S\left(L_{i}\right)}{L_{i}} \frac{\widehat{\rho}}{r} \text { (thus, }\right) \\
\rho>\widehat{\rho}\left(1+\frac{\alpha}{(1-\alpha)} \frac{\theta S\left(L_{i}\right)}{r L_{i}}\right) \equiv \widetilde{\rho}
\end{gathered}
$$

Eq. (6) shows that the MB's default rate is higher than the PB's in Eq. (2) and is dependent on the balance between the two components of the utility function. In other words, MBs are able to accept a higher level of nonperforming loans, and the threshold value is greater if the mutual component is weighted more than the profits one. As for PBs, the term $\rho$ in Eq. (5) can be thought of as an inverse measure of information accuracy. We assume that MBs and PBs compete à la Cournot on the loan market. By simultaneously maximizing Eqs. (1) and (4) with respect to $\left(L_{i}\right)$ for MBs and to $\left(L_{j}\right)$ for PBs, we obtain the following reaction functions ${ }^{7}$ :

\footnotetext{
${ }^{6}$ We can assume that the majority of members' borrowers are also savers in Italian cooperative banks as highlighted in Amendola (2012).

${ }^{7}$ We consider now that members' utility is represented by consumers' surplus that is derived directly from the linear demand function for loans. For a different specification of members' utility see Appendix A.4.
} 


$$
\begin{gathered}
R F_{j}\left(L_{i}\right)=\frac{(1-\rho)\left(a-N L_{i}\right)-\lambda \rho}{(M+1)(1-\rho)} \\
R F_{i}\left(L_{j}\right)=\frac{(1-\alpha)\left((1-\rho)\left(a-M L_{j}\right)-\rho \lambda\right)}{((1-\alpha)(1-\rho)(N+1)-\alpha \theta)}
\end{gathered}
$$

There is a peculiarity in the two types of banks' reaction functions that is common in a Cournot strategic interaction; the PB's reaction function slopes downward (9). Conversely, the MB's reaction function slope depends, as Delbono and Scarpa (1995) also noted, on the mutual component of the pay-off function (10).

$$
\begin{gathered}
R F_{j}^{\prime}\left(L_{i}\right)=-\frac{\frac{\partial^{2} U_{j}}{\partial L_{j} L_{i}}}{\frac{\partial^{2} U_{j}}{\partial L_{j}^{2}}}<0 \\
R F_{i}^{\prime}\left(L_{j}\right)=-\frac{\frac{\partial^{2} U_{i}}{\partial L_{i} L_{j}}}{\frac{\partial^{2} U_{i}}{\partial L_{i}^{2}}}\left\{\begin{array}{l}
>0 \text { if }>\frac{(1-\alpha)}{\alpha}(1-\rho)(N+1) \\
<0 \text { if }<\frac{(1-\alpha)}{\alpha}(1-\rho)(N+1)
\end{array}\right.
\end{gathered}
$$

The reaction function will slope upward if the fraction of members that are borrowers is greater

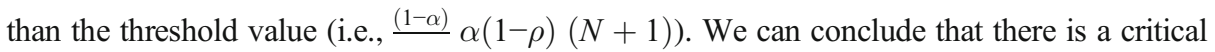
value of the fraction of members such that if $\theta>\widetilde{\theta}$, then the MB will behave like a PB that maximizes members' welfare, as Delbono and Rossini (1991) also noted. In this case, consistent with its main goal, the utility function of the MB will be convex for the quantity of loans. ${ }^{8}$

Furthermore, since $0<\theta<1$, this event happens only for a range of values of $\alpha$ and $N$ (e.g. $\frac{(1-\alpha)}{}$ $\alpha(1-\rho)(N+1)<1$ for $\left.\frac{1-\rho}{2-\rho}<\alpha<1 \& 0 \leq N \leq \frac{2 \alpha-1+\rho(1-\alpha)}{(1-\alpha)}(1-\rho)\right)$. If the second condition holds, then the MBs' reaction function also slopes downward.

Since we are interested in changes in the market structure and their effect on stability, we consider an increase in the number of competitors and its effect on the default rate $\widehat{\rho}$ for each bank, given the equilibrium values of loans (see Appendix A.2).

We can thus consider a variation in the level of concentration as a shift from one market structure to another.

\section{Results and Discussion}

In this Section, we first consider the effect of an increase in the level of the interest rate on default rates: for the PBs, $\frac{\widehat{\partial \rho}}{\partial r}=\frac{\lambda}{(r+\lambda)}^{2}>0$, and for MBs, $\frac{\widetilde{\partial \rho}}{\partial r}=S \alpha \theta+L_{i}(-1+\alpha) \frac{\lambda}{L_{i}(-1+\alpha)(r+\lambda)}$ ${ }^{2}>0$ if $S>0 ; L_{i}>0 ; 0 \leq \theta \leq \frac{L_{i} \lambda(1-\alpha)}{S \alpha} \equiv \theta^{\iota}$.

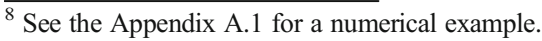


The first finding is that an increase in the level of the interest rate increases stability for PBs since it increases the default rate that is tolerable to the bank. For MBs, this effect depends on the fraction of members that are borrowing from the bank. In other words, if $\theta<\theta$, as for PBs, an increase in $r$ increases stability. If $\theta>\theta$, an increase in the interest rate lowers the default rate tolerable to MBs and they become less stable.

Consider now the total effect on the interest rate due to an increase in the number of competitors, through its effect on the equilibrium level of loans, $r=\frac{\partial r}{\partial N} d N+\frac{\partial r}{\partial M} d M^{9}$.

An increase in the number of MBs and PBs increases $\mathrm{r}$ if $\widetilde{\alpha} \equiv \frac{1-\rho}{1-\rho+\theta}<\alpha<(3-\rho) \frac{\left(1-\rho^{2}\right)}{2 \theta+(3-\rho)}$ $\left(1-\rho^{2}\right) \equiv \alpha$ and the interval narrows as $\rho$ increases. In other words, a decrease in concentration increases $r$ only for a special interval of values of the weight assigned by the MB to the members' component of the utility. As the nonperforming loans increase, this condition becomes more stringent and lowers the range of feasible values. However, a decrease in concentration determines a reduction in the interest rate on loans if $\alpha<\widetilde{\alpha}$.

We come to the following conclusions when we consider the effect of the number of competitors on the default rate for each type of bank:

L.1 A reduction in concentration (i.e., an increase in the number of competitors) increases stability for PBs, if the weight assigned by MBs to the members' component of the utility belongs to the interval $\widetilde{\alpha}<\alpha<\alpha^{v}$. A reduction in concentration decreases stability for PBs if $\alpha<\widetilde{\alpha}$.

Since the default rate of PBs always increases with $r$, for the PBs to be more stable when concentration decreases, a positive correlation between $r$ and the number of banks in the market needs to exist. An increase in the number of MBs and PBs increases $\mathrm{r}$ if $\widetilde{\alpha}<\alpha<\alpha$ and the interval narrows as $\rho$ increases. On the other hand, if the weight assigned by the MB to the members' component of the utility is $\alpha<\widetilde{\alpha}$, then the interest rate decreases as concentration decreases and the level of nonperforming loans tolerated by PBs decreases that makes them less stable.

L.2 When the fraction of members who are borrowers in an $M B$ is lower than the threshold value $(\theta<\theta)$, then a reduction in concentration increases stability for MBs if $\widetilde{\alpha}<\alpha<\alpha$ and members' surplus is higher than the threshold value $S>\frac{L \lambda(1-\alpha)}{\alpha}$. A reduction in concentration decreases stability for $M B$ s if $\alpha<\widetilde{\alpha}$.

L.3 When the fraction of members who are borrowers in an $M B$ is higher than the threshold value $(\theta>\theta)$, then a reduction in concentration decreases stability for MBs, if $\widetilde{\alpha}<\alpha<\alpha$ . On the other hand, a reduction in concentration increases stability for MBs if $\alpha<\widetilde{\alpha}$.

For examples of L.2 and L.3, we consider the effect of an increase in the interest rate on MBs' default rate:

$$
\frac{\partial \widetilde{\rho}}{\partial r}>0 \text { if } S>\frac{L \lambda(1-\alpha)}{\alpha} \text { and } 0<\theta<\frac{L \lambda(1-\alpha)}{S \alpha}
$$

\footnotetext{
${ }^{9}$ See the Appendix A.3 for details on the effect of an increase in $\mathrm{N}$ and $\mathrm{M}$ on the interest rate.
} 


$$
\frac{\partial \widetilde{\rho}}{\partial r}<0 \text { iff }>\frac{L \lambda(1-\alpha)}{\alpha} \text { and } \frac{L \lambda(1-\alpha)}{S \alpha}<\theta \leq 1 .
$$

When concentration decreases, two situations make MBs more stable:

1) Either the two following conditions hold:

a. $\quad d r>0 \widetilde{\alpha}<\alpha<\alpha$

$$
\frac{\partial \widetilde{\rho}}{\partial r}>0 S>\frac{L \lambda(1-\alpha)}{\alpha} \text { and } \theta<\frac{L \lambda(1-\alpha)}{S \alpha}
$$

2) Or:

$$
\begin{gathered}
d r<0 \quad \text { if } \alpha<\widetilde{\alpha} . \\
\frac{\partial \widetilde{\rho}}{\partial r}<0 \text { if } S>\frac{L \lambda(1-\alpha)}{\alpha} \text { and } \frac{L \lambda(1-\alpha)}{S \alpha}<\theta
\end{gathered}
$$

Thus, when concentration decreases, the weight assigned by an MB to the members' component should be in the interval $\widetilde{\alpha}<\alpha<\alpha$, and the fraction of members' borrowers must be lower than the threshold value $\theta<\theta$. Moreover, a condition on the surplus should be $S>\widetilde{S}$.

Further, the effect of a lower concentration level on the interest rate may lead to a reduction in $\mathrm{r}$ if $\alpha<\widetilde{\alpha}$. In this case MBs can still be more stable if $\frac{\partial \tilde{\rho}}{\partial r}<0$, when $S>\widetilde{S}$ and $\theta^{\iota}<\theta$ such that a decrease in the interest rate increases the default rate for the MBs that lowers their risk of failure. This case does not apply to PBs.

From the results highlighted by L.1, L.2, and L.3, we can derive the following propositions:

P.1 When the fraction of MBs' members who are borrowers is lower than the threshold value $\theta<\theta^{\sim}$ and if $\widetilde{\alpha}<\alpha<\alpha^{\nu}$, then both the MBs and PBs are more stable if concentration decreases.

This proposition is verified by the results described in L.1 and L.2: namely, when $\theta<\theta$, an increase in $r$ due to a reduction in concentration induces the same effect for both banks on the threshold value of the default rate. Both types of bank are more stable.

P.2 When the fraction of MBs' members who are borrowers is higher than the threshold value $\theta>\theta$, then a reduction in concentration reduces stability for one group and increases stability for the other group. In particular, when reduction in concentration leads to an increase in the level of $r(\widetilde{\alpha}<\alpha<\alpha$,), then MBs are less stable while PBs are more stable. On the other hand, when the reduction in concentration leads to a reduction in the level of $r(\alpha<\widetilde{\alpha})$, then MBs are more stable but PBs are less stable. 
P.2 is verified if we combine the results in L.1 and L.3. An increase in $r$ due to a reduction in concentration increases stability only for PBs. On the other hand, a reduction in $r$ increases stability only for MBs.

In conclusion, when the fraction of MBs' members who are borrowers is lower than the threshold value $\theta<\theta$, both MBs and PBs are more stable if the market structure is less concentrated: if the level of the interest rate rises, then it increases (for both types of bank) the level of the threshold value for nonperforming loans that corresponds to a bank's default situation.

When the fraction of MBs' members who are borrowers is higher than the threshold value $\theta>\theta$, then a reduction in concentration reduces stability for one group and increases stability for the other group. In particular, when the reduction in concentration increases the level of $r$, MBs are less stable while PBs are more stable. This situation may be due to the fact that the fraction of MBs' borrower members is higher (MBs are dominated by borrowers). However, a reduction in concentration that reduces the level of $r$ makes MBs more stable (since borrower members are better off) but PBs are less stable (their profits are lower).

\section{Empirical Design}

\subsection{Financial Stability and Bank Market Concentration: A Stochastic Frontier Approach}

In this subsection, in order to evaluate and investigate the relation indicated by the previous theoretical model, i.e. the effect of market structure on financial stability, we perform an empirical analysis based on a parametric approach (Tabak et al., 2012) by using the recent stochastic frontier technique developed by Kumbhakar et al. (2014). This model splits the error term into four components: bank fixed effects, time-varying inefficiency, time-invariant inefficiency, and a stochastic component that captures random shocks. With this model, we capture the fact that banks can eliminate certain sources of their short-term inefficiency over time, while other sources can have a more permanent nature. The empirical model is represented by the following set of equations:

$$
\begin{gathered}
y_{i t}=f\left(x_{i t}, \beta_{i t}\right)+\varepsilon_{i t} \\
\varepsilon_{i t}=v_{i t}-u_{i t}+\alpha_{i}+E\left(u_{i t}\right)+\alpha_{0}^{*} \\
\alpha_{i}=\mu_{i}-\eta_{i}+E\left(\eta_{i}\right) \\
\alpha_{0}^{*}=\alpha_{0}-E\left(\eta_{i}\right)-E\left(u_{i t}\right) \\
v_{i t} \sim \text { i.i.d.N }\left(0, \sigma_{v}^{2}\right) \\
u_{i t} \sim \text { i.i.d. } N^{+}\left(\mathrm{z}_{\mathrm{i}} \delta, \sigma_{u}^{2}\right)
\end{gathered}
$$




$$
\begin{gathered}
\mu_{i} \sim i . i . d . N\left(0, \sigma_{\mu}^{2}\right) \\
\eta_{i} \sim \text { i.i.d. } N^{+}\left(0, \sigma_{\eta}^{2}\right)
\end{gathered}
$$

where $y$ denotes the output of the $\mathrm{i}_{\text {th }}$ bank (the z-score), $x_{i}$ represents the $1 \mathrm{xk}$ vector of input, $\beta$ is the kx1 vector of unknown parameters to be estimated, $\eta_{i}$ represents persistent inefficiency, $\mu_{i}$ captures bank effects, and $v_{i t}$ is a stochastic component. The $u_{i t}$ denotes the short-term inefficiency distributed by each unit as a truncation at zero, where $\mathrm{z}$ is a $(1 \mathrm{x} \mathrm{m})$ vector of exogenous factors associated with the technical inefficiency of production units (see Table 1 for more details about these exogenous factors $)^{10}$, and $\delta$ is a $(m \times 1)$ vector of unknown coefficients. This approach, unlike others, makes possible the consideration of how the production process of banks, and therefore the degree of allocation of resources, affects the probability of bankruptcy.

This model is estimated in three steps. First, Eq. (13) is estimated using a standard fixed effects estimation. Second, time-varying inefficiency $u_{i t}$ is obtained. Third, persistent inefficiency $\eta_{i}$ is estimated (Kumbhakar et al. 2014). Specifically, the Translog specification is described as follows:

$$
\begin{aligned}
\frac{\widetilde{F S}}{\widetilde{w}_{1 .}}= & \sum_{j} \beta_{j} \widetilde{y}_{j .}+\sum_{k} \gamma_{k}\left(\frac{\widetilde{w}_{k .}}{\widetilde{w}_{1 .}}\right)+\tau_{1} T \\
& +\frac{1}{2}\left[\sum_{j} \sum_{m} \beta_{j m} \widetilde{y}_{j .} \widetilde{y}_{m .}+\sum_{k} \sum_{n} \gamma_{k n}\left(\frac{\widetilde{w}_{k .}}{\widetilde{w}_{1 .}}\right) *\left(\frac{\widetilde{w}_{n .}}{\widetilde{w}_{1 .}}\right)+\tau_{11} T^{2}\right] \\
& +\sum_{j} \sum_{k} \delta_{j k} \widetilde{y}_{j}\left(\frac{\widetilde{w}_{k .}}{\widetilde{w}_{1 .}}\right)
\end{aligned}
$$

where $\widetilde{F S}$ is the natural logarithm of financial stability calculated using the $\mathrm{z}$-score, $\widetilde{y}$ are (the natural logs of) output quantities, $\widetilde{w}$ are (the natural logs of) input prices, and T denotes a time trend that captures changes in technology over time. The linear homogeneity in factor prices is guaranteed by dividing all input prices and total cost by one input price (in our case, labour cost, $\left.\widetilde{w}_{1}\right)$. Moreover, symmetry conditions are also imposed: $\beta_{j m}=\beta_{m j}$ and $\gamma_{k n}=\gamma_{n k}$.

As suggested in the literature, the z-score measure is considered a good proxy of a bank's distance from default (Rojas-Suarez, 2002), and it does not require strong assumptions about the distribution of the returns on assets (Strobel, 2011). It combines banks' buffers (capital and profits) with the risks they face (measured by the standard deviation of returns) that reflect the number of standard deviations by which returns would have to fall from the mean in order to wipe out equity. A higher $\mathrm{z}$-score value means a lower probability of insolvency risk (Unde and Heimeshoff, 2009) and greater stability (e.g., inverse of the probability of defaults) that provides a direct measure of the banking system's stability. The z-score then increases with the banks' profitability and capital ratio and, conversely, decreases with increases in the conditional volatility.

${ }^{10}$ As suggested by Lind and Mehlum (2010) test in Appendix A.5, we also include the square of the market structure in the inefficiency component. 
Table 1 Description of the variables. This Table presents the main variables we employ in our empirical analysis. The source is BilBank 2000 database from ABI

\begin{tabular}{|c|c|c|}
\hline Variables & Symbol & Description \\
\hline \multicolumn{3}{|l|}{ Financial Stability } \\
\hline Financial Stability on ROA & $\mathrm{FS}_{\mathrm{ROA}}$ & $\begin{array}{l}\text { Capitalisation plus return on assets over standard } \\
\text { deviation of return on assets. }\end{array}$ \\
\hline Financial Stability on ROE & $\mathrm{FS}_{\mathrm{ROE}}$ & $\begin{array}{l}\text { One plus return on equity over standard deviation of } \\
\text { return on equity. }\end{array}$ \\
\hline \multicolumn{3}{|l|}{ Market structure } \\
\hline Market structure index & HHI & $\begin{array}{l}\text { Market structure of banks based on bank specific } \\
\text { customer loans to total customer loans at LMA } \\
\text { level (see eq. 22). }\end{array}$ \\
\hline Market power index & MS & $\begin{array}{l}\text { Market power of banks based on bank specific } \\
\text { customer loans to total customer loans at LMA } \\
\text { level (see eq. 23). }\end{array}$ \\
\hline \multicolumn{3}{|c|}{ Determinants of Financial Stability } \\
\hline Capitalisation & ETA & Equity to total assets. \\
\hline Dimension of bank & $\ln (\mathrm{TA})$ & Log of total assets. \\
\hline Macro area & MACRO & $\begin{array}{l}\text { South\&Islands (SI), North-West }(\mathrm{N}-\mathrm{W}) \text { and } \\
\text { North-East }(\mathrm{N}-\mathrm{E}) \text { dummies; Centre }(\mathrm{CE}) \text { as } \\
\text { benchmark group. }\end{array}$ \\
\hline Type of banks & TYPE & $\begin{array}{l}\text { Mutual Cooperative Banks (MB) and profit oriented } \\
\text { banks (PB) banks dummies (commercial and } \\
\text { popular; popular used as benchmark group). }\end{array}$ \\
\hline Dimension of banks & DYM & $\begin{array}{l}\text { Large, medium, small and minor dummies; major } \\
\text { used as benchmark group. }\end{array}$ \\
\hline Time & $\mathrm{T}$ & Time trend (1994-2015) \\
\hline
\end{tabular}

Because they are mathematically equivalent, the choice of the normalizing variable is innocuous (Restrepo-Tobòn and Kumbhakar, 2017). The set of parameters in the Translog function are estimated using a maximum likelihood estimator (MLE) that gives a consistent and efficient estimator, as suggested by Kumbhakar and Lovell (2000).

To examine the effect of market structure on financial stability, we include in the inefficiency component the Herfindahl index that is calculated as the sum of squared market shares in terms of total loans of all banks in the same labor market area (HHI):

$$
H H I_{i, t}=\sum_{i=1}^{N}\left(\frac{\text { Loans }_{i, t}}{\text { Total Loans } k, t}\right)^{2}
$$

where Loans ${ }_{i}$ refers to the customer loans of bank $i$ at time $t$, and Total Loans $s_{k}$ refers to the total customer loans grouped at the $\mathrm{k}$ labor market level at time $\mathrm{t}$, because it is reasonable that banks compete with other intermediaries operating in the surrounding areas. ${ }^{11}$ In a perfect competition market, the HHI approaches zero. The further the HHI is from zero, the closer the area's market is to a monopoly.

We reduce the heterogeneity in our estimation because our analysis is based on a single country, thereby accounting for cultural, geographical, political, and monetary homogeneity. Moreover, the highly detailed spatial stratification enables us to capture the differences between geographical areas that result in more accurate estimates.

\footnotetext{
${ }^{11}$ For robustness, we also measure the Herfindahl index in terms of total assets and total deposits. Due to space constraints, the results (available on request) are not reported.
} 


\subsection{Data and Variables}

The data come from the BilBank 2000 database distributed by the ABI (Associazione Bancaria Italiana) because of its large time extension and its rich set of information on bank balance sheets for the period from 1994 to 2015 (see Table 1 for more details on the definition of the variables). ${ }^{12}$ We focus on the Italian context due to the availability of highly disaggregated territorial data, the financial reforms (privatization and Second Banking Directive) that occurred after 1990, and its integration of markets.

The sample of banks consists of MBs and PBs, but not Italian branches of foreign banks. In particular, we use a sample of Italian banks classified by the Bank of Italy as follows: major (average funds intermediated more than 65 billion euro), large (average funds intermediated between 27 and 65 billion euro), medium (average funds intermediated between 9 and 27 billion euro), small (average funds intermediated between 1.3 and 9 billion euro), and minor (average funds intermediated less than 1.3 billion euro). We also thus consider the different sizes of financial institutions.

Table 2 has a description of the sample used in the analysis by geographical location that emphasizes the importance of MBs to the Italian banking scene; indeed, almost $66 \%$ of financial institutions in our sample consist of MBs that makes them very important players and actors in the Italian financial environment. To obtain a complete picture of territorial and banking differences, we also have included in the table some descriptive statistics on the cost, profit and risk measures as well as having included a composite measure of the outputs, inputs, and input prices ${ }^{13}$.

According to the calculation of bank performance, our production set follows the asset model (Sealey and Lindley 1997) in which the output vector (y) comprises customer loans $\left(\mathrm{y}_{1}\right)$; services (administrative) or non-traditional activities that are commission income and other operating income $\left(\mathrm{y}_{2}\right)$; and securities $\left(\mathrm{y}_{3}\right)$ that are bank loans, Treasury bills, and similar securities, bonds, and other debtless bonds; and debt securities held by banks and other financial institutions. Because non-traditional activities play an important role in banking output, we include a proxy to capture the effect of these activities, such as commission income and other operating income, on bank performance (e.g., Casu et al., 2004; Tortosa-Ausina et al., 2008). Instead, the input vector (x) consists of the following items: number of workers $\left(\mathrm{x}_{1}\right)$; number of branches $\left(\mathrm{x}_{2}\right)$; and total liabilities to customers, amounts owed to banks, and debt securities $\left(\mathrm{x}_{3}\right)$. The cost vector $(\mathrm{w})$ incurred by the credit institutions is composed of the labor cost $\left(\mathrm{w}_{1}\right)$ that is the ratio of personnel expenses to the number of employees; cost of physical capital $\left(\mathrm{w}_{2}\right)$ that is the ratio of other administrative expenses, value adjustments to tangible and intangible assets, and other operating expenses to the number of branches; and the cost of financial capital $\left(\mathrm{w}_{3}\right)$ that consists of interest expenses and similar charges and commission expenses over total liabilities (see Table 3 for more details on descriptive statistics on input, input prices and output). On the output side, PBs have a lower value of customer loans $\left(\mathrm{y}_{1}\right)$, of level of services $\left(\mathrm{y}_{2}\right)$, and of other loans $\left(\mathrm{y}_{3}\right)$. With regard to geographic

\footnotetext{
${ }^{12}$ Unfortunately, we do not have information on some of the variables used in the analysis for the years before 1994 and after 2015. For this reason, we base our analysis on the 1994-2015 time span. Furthermore, the ABI data set is compared with the Bankscope data set. The debate is in favor of the former because it has some valuable information, such as number of branches and number of workers, that is necessary to evaluate the input prices for each bank.

${ }^{13}$ Note that in our sample the number of banks dropped drastically during the period considered, probably due both the lack of information and to mergers and acquisitions (M\&A).
} 
location, banks located in the Northern regions (i.e. North-West $(\mathrm{N}-\mathrm{W})$ and North-East $(\mathrm{N}-\mathrm{E})$ ) have a high level of customer loans $\left(\mathrm{y}_{1}\right)$, of services $\left(\mathrm{y}_{2}\right)$, and of other loans $\left(\mathrm{y}_{3}\right)$ than CentralSouthern\&Islands (i.e. Centre (CE) and South-Islands (SI)). The costs of labor $\left(\mathrm{w}_{1}\right)$, physical $\left(\mathrm{w}_{2}\right)$, and financial $\left(\mathrm{w}_{3}\right)$ are higher for PBs and for banks operating in the Northern regions. PBs have a greater number of workers $\left(\mathrm{x}_{1}\right)$ and branches $\left(\mathrm{x}_{2}\right)$ and a higher level of liabilities $\left(\mathrm{x}_{3}\right)$.

Recent studies have strongly approved of the inclusion of some environmental and bankspecific variables in a one-stage stochastic frontier (Lozano-Vivas et al., 2002, Hasan et al., 2009), particularly when considering the Italian context (Destefanis et al., 2014; Barra et al., 2016). Therefore, we include in the z-vector associated with the technical inefficiency of production units for the following environmental and bank-specific factors: (i) bank size as measured by the natural logarithm of total assets (TA); (ii) bank capitalization as measured by the ratio of equity to total assets (ETA); (iii) typology of banks such as MBs and PBs in which popular banks are used as the benchmark group; (iv) macro areas such as North-West (N-W), North-East (N-E), and South\&Islands (SI), while Central (CE) is used as a benchmark to control for any unobservable territorial effects; and (v) the typology of major, large, medium, small, and minor. We use major group as a benchmark for the different sizes of financial institutions. Further, we include a time trend and its square to control for any unobservable shocks that affect the inefficiency of financial stability. For a comparison check, the Italian Statistical Office (ISTAT 2005), being a public research body and the main provider of official statistics to support citizens and decision-makers, currently identifies 110 provinces (the NUTS3 category) and 686 LMAs (labor market areas). These classifications highlight remarkable differences in economic performance across the Italian territory. LMA-level data for branches, deposits, and loans come from the Bank of Italy data set (Bollettino Statistico). Thus, LMAs represent a deeper territorial disaggregation than NUTS 3 level subdivisions that are sub-regional areas where the bulk of the labor force lives and works (Destefanis et al. 2014; Barra and Zotti, 2019). The other variables useful for our analysis come from the BilBank 2000 database. All monetary aggregates are in thousands of deflated 2005 euros. Our sample begins in 1994, because bank data are not available before that year. The test and SFA regressions are performed using STATA 13.1.

The descriptive statistics confirm that the Northern regions have the financial institutions that are bigger in terms of dimension (related to TA), are more stable (related to $\mathrm{FS}_{\mathrm{ROA}}$ ), and have a higher level of capital (related to ETA) than Central-Southern\&Islands regions. Furthermore, according to the typology of banks, the statistics confirm that stability is driven by the presence of MBs in the market. In fact, MBs show some different territorial and financial characteristics to PBs (Destefanis et al. 2014). As expected, PBs present a level of total assets (TA) higher than that of MBs. On the other hand, MBs show a level of capitalization (ETA) higher than PBs due to their amount of total assets. According to the market structure, Northern regions are less concentrated than Central-Southern\&Islands regions. Moreover, MBs are more concentrated than PBs, both in the case of HHI and MS indicators. These differences are more marked when separate markets are considered Table 4.

\section{Empirical Results}

The theoretical results highlight a negative relation between concentration and stability that depends on some conditions for MBs members' structure. To confirm our theoretical 


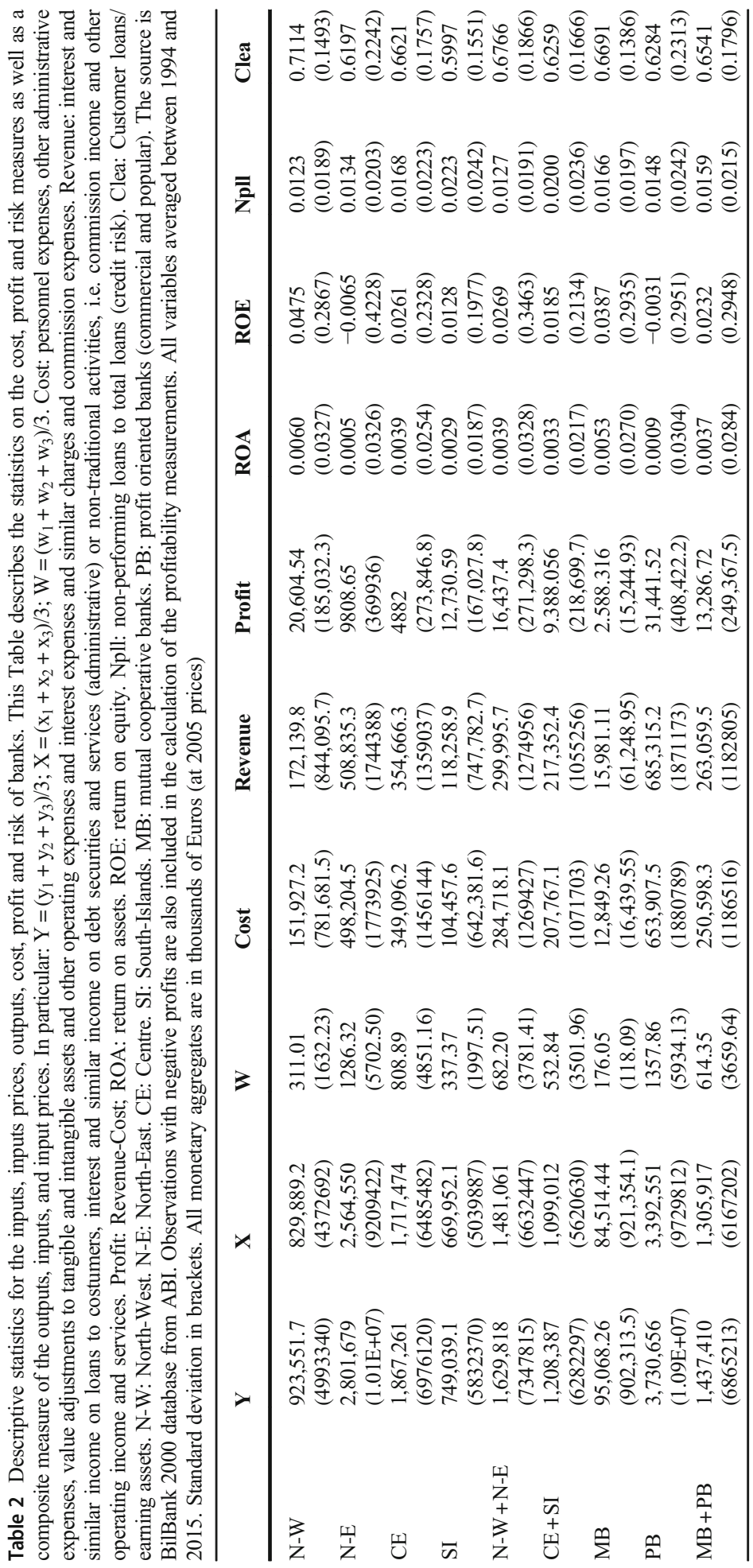




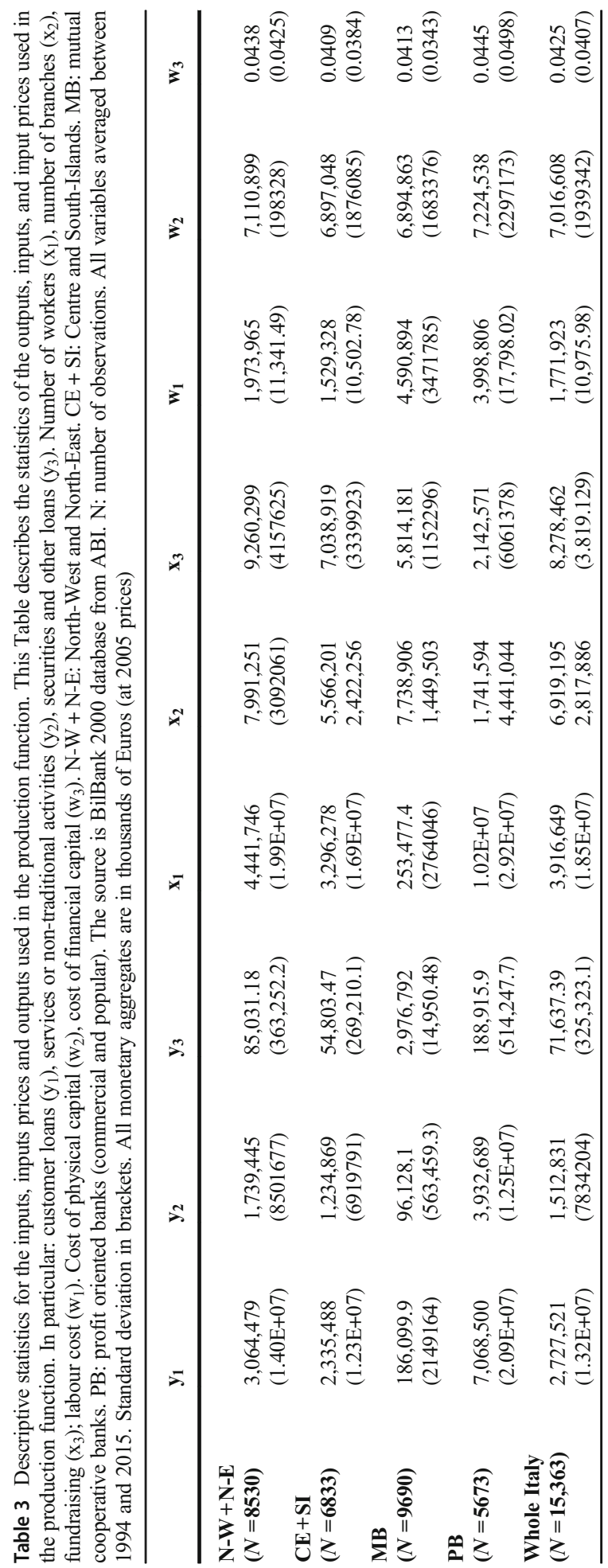


predictions, we conduct an empirical exercise in which we estimate the relation between market structure and the inefficiency of financial stability using a parametric approach (SFA) (see Tabak et al. 2012 for a similar approach). ${ }^{14}$ In order to get closer to the theoretical model, we assume that the MBs and PBs compete in the same market. Taking the inefficiency of financial stability (based on the ROA) as the dependent variable and the $\mathrm{HHI}$ as the main market structure indicator, we observe that the inefficiency decreases in a more concentrated market (similar to Keeley 1990; Allen and Gale 2000, 2004; Beck et al. 2006a; Matsuoka 2013; Barra and Zotti, 2019), but when the square of the HHI is considered, the inefficiency increases; we find a U-shaped relation between market structure's concentration and the inefficiency of financial stability (Table 5, column A1). In other words, banks that operate under low concentration levels are less fragile in terms of the inefficiency of stability (similar to Tabak et al. 2012). As a robustness check, we assess the same model but use the MS that is calculated by using the loans as follows:

$$
M S_{i, t}=\sum_{i=1}^{N}\left(\frac{\text { Loans }_{i, t}}{\text { Total Loans }_{k, t}}\right)
$$

where Loans $\mathrm{s}_{\mathrm{i}}$ refers to the customer loans of bank i over time $\mathrm{t}$, and the Total Loans $\mathrm{s}_{\mathrm{k}}$ refers to total customer loans grouped at the $\mathrm{k}$ level of the labor market over time $\mathrm{t}$. We observe that the inefficiency of financial stability decreases when the MS is high, but when its square is considered, the inefficiency increases; in this case, the finding also indicates the presence of a U-shaped relation between market concentration and the inefficiency of financial stability (Table 5, column A3).

As regards the control variables, particular attention should be given to the total assets (TA) that is a good proxy for the banking dimension and to equity on total assets (ETA) that is a good proxy for bank capitalization. The signs of these two controls are negative and significant in all the estimations performed and thereby indicate that greater size and capitalization are important drivers in reducing the inefficiency of stability. We also find that the presence of MBs in the market reduces this inefficiency compared to the presence of PBs.

\section{Conclusions and Policy Implications}

In recent years, both theoretical and empirical studies on credit markets have devoted attention to analysing the relation between the structure of the credit market and the financial stability of banks (Allen and Gale, 2004; Boyd and De Nicoló, 2006; Fu and Heffernan, 2009; Koutsomanoli-Filippaki et al., 2009; Fang et al., 2011). As previously discussed, both economic theory and empirical evidence provide contrasting results on this relation. Occasionally, there appears to be a negative trade-off between concentration and financial stability. Moreover, since the 2008-2009 financial crisis, studies have found that MBs play a stabilizing role in the banking system as a whole. This study makes two original contributions to the

\footnotetext{
${ }^{14}$ For robustness, we also investigated the relation between financial stability and market structure using a pooled OLS (ordinary least squares) and FE (fixed effects) estimators. Moreover, we have estimated the models using a different measure of bank stability that can capture the banks' distance from default. This measure relates to the distance between total loans and nonperforming loans. The higher this difference is, the lower the probability of failure. In other words, the percentage of nonperforming loans is low, thereby not affecting the probability of bank failure. Overall, the empirical findings are confirmed. For space purposes, we do not display the results but they are available on request.
} 


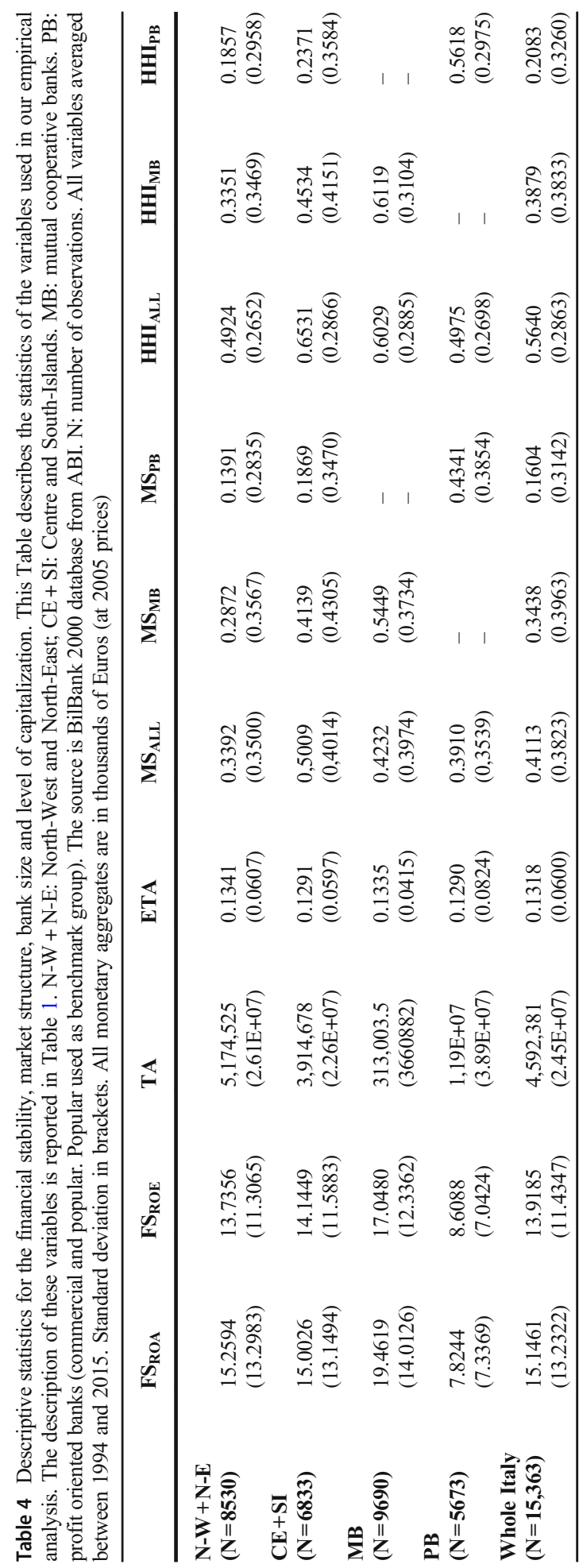


literature: first, by analysing the relation between market structure and financial stability from both a theoretical and an empirical point of view; second, by considering the peculiar polymorphism that characterizes the credit market in which at least two main types of bank operate: PBs and MBs. Despite the consistently strong findings about the differences between

Table 5 Inefficiency of stability and market structure. The indirect approach (SFA). The description of these variables is reported in Table 1. Standard errors in brackets

\begin{tabular}{|c|c|c|c|c|}
\hline & (A1) & (A2) & (A3) & (A4) \\
\hline & $\ln \left(\mathrm{FS}_{\mathrm{ROA}} / \mathbf{w}_{1}\right)$ & $\ln \left(\mathrm{FS}_{\mathrm{ROA}} / \mathbf{w}_{1}\right)$ & $\ln \left(\mathrm{FS}_{\mathrm{ROA}} / \mathbf{w}_{1}\right)$ & $\ln \left(\mathrm{FS}_{\mathrm{ROA}} / \mathrm{w}_{1}\right)$ \\
\hline & $X=H H I$ & $\mathbf{X}=\mathbf{H H I}$ & $\mathbf{X}=\mathbf{M S}$ & $\mathbf{X}=\mathbf{M S}$ \\
\hline & One Market & Two Markets & One Market & Two Markets \\
\hline \multicolumn{5}{|c|}{ Determinants of inefficiency of stability } \\
\hline \multirow[t]{2}{*}{ MB } & $-0.443^{* * *}$ & $-0.526^{* * *}$ & $-0.442^{* * *}$ & $-0.489^{* * *}$ \\
\hline & {$[0.0708]$} & {$[0.0780]$} & {$[0.0706]$} & {$[0.0824]$} \\
\hline \multirow[t]{2}{*}{ PB } & $1.418^{* * * *}$ & $1.406^{* * *}$ & $1.405^{* * * *}$ & $1.386^{* * * *}$ \\
\hline & [0.0694] & {$[0.0683]$} & {$[0.0682]$} & {$[0.0665]$} \\
\hline \multirow[t]{2}{*}{ Large } & $-0.344^{* * * *}$ & $-0.345^{* * * *}$ & $-0.350^{* * * *}$ & $-0.350^{* * * *}$ \\
\hline & {$[0.0775]$} & {$[0.0777]$} & {$[0.0769]$} & {$[0.0767]$} \\
\hline \multirow[t]{2}{*}{ Medium } & $-0.770^{* * * *}$ & $-0.763^{* * *}$ & $-0.770^{* * * *}$ & $-0.756^{* * *}$ \\
\hline & {$[0.0977]$} & [0.0979] & {$[0.0971]$} & [0.0972] \\
\hline \multirow[t]{2}{*}{ Small } & $-1.071^{* * *}$ & $-1.039^{* * *}$ & $-1.071^{* * * *}$ & $-1.028^{* * * *}$ \\
\hline & {$[0.131]$} & {$[0.131]$} & {$[0.130]$} & {$[0.130]$} \\
\hline \multirow[t]{2}{*}{ Minor } & $-1.195^{* * *}$ & $-1.158^{* * *}$ & $-1.196^{* * *}$ & $-1.152^{* * *}$ \\
\hline & {$[0.160]$} & [0.159] & {$[0.159]$} & [0.158] \\
\hline \multirow[t]{2}{*}{$\mathrm{N}-\mathrm{W}$} & $-0.0748^{*}$ & -0.0684 & -0.0621 & -0.0532 \\
\hline & [0.0417] & [0.0417] & [0.0413] & [0.0413] \\
\hline \multirow[t]{2}{*}{ N-E } & $0.296^{* * * *}$ & $0.293^{* * * *}$ & $0.293^{* * * *}$ & $0.286^{* * *}$ \\
\hline & {$[0.0501]$} & {$[0.0501]$} & [0.0496] & {$[0.0497]$} \\
\hline \multirow[t]{2}{*}{ SI } & 0.0302 & 0.0327 & 0.0321 & 0.0385 \\
\hline & [0.0486] & {$[0.0490]$} & [0.0485] & [0.0489] \\
\hline \multirow[t]{2}{*}{$\ln (\mathrm{TA})$} & $-0.176^{* * * *}$ & $-0.173^{\text {**** }}$ & $-0.167^{* * * *}$ & $-0.158^{\text {**** }}$ \\
\hline & {$[0.0240]$} & {$[0.0236]$} & [0.0238] & [0.0234] \\
\hline \multirow[t]{2}{*}{ ETA } & $-11.11^{* * * *}$ & $-10.96^{* * *}$ & $-11.01^{* * * *}$ & $-10.83^{* * *}$ \\
\hline & {$[0.553]$} & {$[0.550]$} & {$[0.547]$} & {$[0.540]$} \\
\hline \multirow[t]{2}{*}{$\mathrm{T}$} & $-0.0322^{* *}$ & $-0.0350^{* *}$ & $-0.0327^{* *}$ & $-0.0375^{\text {*** }}$ \\
\hline & {$[0.0140]$} & {$[0.0143]$} & {$[0.0139]$} & {$[0.0144]$} \\
\hline \multirow[t]{2}{*}{$\mathrm{T}^{2}$} & $0.0113^{* * *}$ & $0.0116^{* * *}$ & $0.0112^{* * *}$ & $0.0118^{* * * *}$ \\
\hline & {$[0.00269]$} & {$[0.00275]$} & {$[0.00269]$} & {$[0.00278]$} \\
\hline \multirow[t]{2}{*}{$\mathrm{X}_{(\mathrm{ALL})}$} & $-0.528^{* * * *}$ & - & $-0.673^{* * *}$ & - \\
\hline & {$[0.121]$} & - & {$[0.116]$} & - \\
\hline \multirow{2}{*}{$\mathrm{X}^{2}{ }_{(\mathrm{ALL})}$} & $0.395^{\text {**** }}$ & - & $0.489^{* * * * *}$ & - \\
\hline & [0.117] & - & {$[0.106]$} & - \\
\hline \multirow[t]{2}{*}{$\mathrm{X}_{(\mathrm{MB})}$} & - & -0.239 & - & $-0.643^{* * * *}$ \\
\hline & - & {$[0.202]$} & - & {$[0.224]$} \\
\hline \multirow[t]{2}{*}{$\mathrm{X}_{(\mathrm{MB})}$} & - & 0.204 & - & $0.522^{* * * *}$ \\
\hline & - & {$[0.189]$} & - & {$[0.192]$} \\
\hline \multirow[t]{2}{*}{$\mathrm{X}_{(\mathrm{PB})}$} & - & $-0.815^{* * * *}$ & - & $-0.934^{* * * *}$ \\
\hline & - & {$[0.161]$} & - & {$[0.150]$} \\
\hline \multirow[t]{2}{*}{$\mathrm{X}^{2}{ }_{(\mathrm{PB})}$} & - & $0.580^{* * * *}$ & - & $0.627^{* * * *}$ \\
\hline & - & [0.151] & - & [0.134] \\
\hline \multirow[t]{2}{*}{ Constant } & $4.894^{* * * *}$ & $4.870^{* * * *}$ & $4.833^{* * * *}$ & $4.747^{* * * *}$ \\
\hline & {$[0.379]$} & {$[0.376]$} & {$[0.376]$} & {$[0.373]$} \\
\hline Period & $1994-2015$ & $1994-2015$ & $1994-2015$ & 1994-2015 \\
\hline Observations & 15,267 & 15,267 & 15,267 & 15,267 \\
\hline
\end{tabular}

$* * *, * *$, and $*$ denote significance at $1 \%, 5 \%$ and $10 \%$, respectively 
these two types, relatively few studies have directly examined the strategic interaction of different types of intermediaries (Berger et al., 2004).

The results of the theoretical model depend on the proportion of borrower members of the MBs. The main theoretical finding shows that, under the condition that MBs are not dominated by borrowers, a less concentrated market structure increases the stability of both types of banks (Hesse and Čihák, 2007; Fiordelisi and Mare, 2014).

The empirical analysis contributes by adding evidence on what can be considered a relevant open question. We observe a U-shaped relation in which a less concentrated market structure reduces inefficiency of stability for both types of banks but a more concentrated market structure increases it. ${ }^{15}$

When the concentration is measured separating the two groups of banks (MBs and PBs), the result described above is confirmed that supports the theoretical predictions (Destefanis et al., 2014; Barra and Zotti, 2019). A specific value added by this study is that, by combining theory and empirical evidence, it provides interesting results that might be helpful to policymakers in developing and implementing regulatory policies aimed at promoting competition and preserving financial stability in the banking system (see Mester 2017 for a discussion about changes to bank supervision and regulation in order to promote financial stability). In particular, with regard to the effectiveness of the ongoing reforms of the MBs in some European countries, for example in Italy, the results might be helpful in enhancing the potential role of MBs as buffers against the financial instability in the banking system.

This analysis can be extended to future research on the European area, for example, by focusing on countries with the same financial market characteristics, such as the simultaneous presence of a network of MBs (Hesse and Čihák, 2007; Fiordelisi and Mare, 2014) together with PBs and verify if the results hold or not.

Supplementary Information The online version contains supplementary material available at https://doi.org/ 10.1007/s10693-021-00360-1.

Funding Open access funding provided by Università degli Studi di Salerno within the CRUI-CARE Agreement.

Open Access This article is licensed under a Creative Commons Attribution 4.0 International License, which permits use, sharing, adaptation, distribution and reproduction in any medium or format, as long as you give appropriate credit to the original author(s) and the source, provide a link to the Creative Commons licence, and indicate if changes were made. The images or other third party material in this article are included in the article's Creative Commons licence, unless indicated otherwise in a credit line to the material. If material is not included in the article's Creative Commons licence and your intended use is not permitted by statutory regulation or exceeds the permitted use, you will need to obtain permission directly from the copyright holder. To view a copy of this licence, visit http://creativecommons.org/licenses/by/4.0/.

\section{References}

Allen F, Gale D (2000) Comparing financial systems. MIT Press, Cambridge and London

Allen F, Gale D (2004) Competition and financial stability. J Money Credit Bank 36:453-480

\footnotetext{
$\overline{{ }^{15} \text { In terms of stability, we observe }}$ an inverted U-shaped relation in which a less concentrated market structure increases stability but a more concentrated market structure reduces it.
} 
Ayadi R, Arbak E, De Groen WP, Llewellyn DT (2010) Investigating diversity in the banking sector in Europe: key developments, performance and role of cooperative banks. Brussels: Centre for European Policy Studies Banking and Finance 28:2427-2460

Bain JS (1956) Barriers to new competition: their character and consequences in manufacturing industries. Harvard UP

Barra C, Destefanis S, Lubrano-Lavadera G (2016) Risk and regulation: a difference-in-differences analysis for Italian local banks. Financ Res Lett 17(C):25-32

Barra C, Zotti R (2019) Bank performance, financial stability and market concentration: evidence from cooperative and non-cooperative banks. Annals of Public and Cooperative Economics 90(1):103-139

Beck T, Demirguc-Kunt A, Levine R (2006a) Bank concentration, competition and crisis: first results. J Bank Financ 30:1581-1603

Beck T, Demirgüç-Kunt A, Levine R (2006b) Bank concentration and fragility: impact and mechanics. In: Stulz R, Carey M (eds) The risks of financial institutions National Bureau of Economic Research

Berger AN, Klapper LF, Turk-Ariss R (2009) Bank competition and financial stability. J Financ Serv Res 35:99118

Berger AN, Demirgüç-Kunt A, Levine R, Haubrich JG (2004) Bank concentration and competition: an evolution in the making. J Money Credit Bank 36:433-451

Besanko D, Thakor AV (1993) Relationship banking, deposit insurance and bank portfolio. In: Mayer C, Vives X (eds) Capital markets and financial intermediation. Cambridge University Press, Cambridge, UK, pp 292318

Boot AWA (2000) Relationship banking: what do we know? J Financ Intermed 9(1):7-25

Boyd JH, De Nicolò G, Jalal AM (2006) Bank risk taking and competition revisited: new theory and new evidence. IMF working paper $06 / 297$

Boyd JH, Nicoló GD (2005) The theory of bank risk taking and competition revisited. J Financ 60(3):1329-1343

Broecker T (1990) Credit-worthiness tests and interbank competition. Econometrica 58:429-452

Carletti E, Hartmann P (2003) Competition and financial stability: What's special about banking?, in monetary history, exchange rates and financial markets: essays in honour of Charles Goodhart, vol 2, edited by P. Edward Elgar, Mizen, Cheltenham, UK

Casu B, Girardone C, Molyneux P (2004) Productivity in European banking - a comparison of parametric and non-parametric approaches. J Bank Financ 28:2521-2540

Cioli V, Giannuozzi A (2014) Banche di credito cooperativo e stabilità finanziaria. Un' analisi comparata con le banche commerciali Appendice Economia e diritto del terziario:239-268

Coco G, Ferri G (2010) From shareholders to stakeholders' finance: a more sustainable lending model. International Journal of Sustainable Economy 2(3):352-364

Cordell LR, Macdonald GD, Wohar ME (1993) Corporate ownership and the thrift crisis. J Law Econ 36(2): 719-756

Delbono F, Scarpa C (1995) Upward-sloping reaction functions under quantity competition in mixed oligopolies. Bull Econ Res 47(4):341-346

Dermine J (1986) Deposit rates, credit rates and bank capital: the Klein-Monti model revisited. J Bank Financ 10(1):99-114

De Santis RA, Surico P (2013) Bank lending and monetary transmission in the euro area. Econ Policy 28:423457

Destefanis S, Barra C, Lubrano-Lavadera G (2014) Financial development and economic growth: evidence from highly disaggregated Italian data. Appl Financ Econ 24(24):1605-1615

Elyasiani E, Goldberg LG (2004) Relationship lending: a survey of the literature. J Econ Bus 56:315-330

Emmons WR, Schmid FA (2002) Pricing and dividend policies in open credit cooperatives. Journal of Institutional and Theoretical Economics (JITE) / Zeitschrift für die gesamte Staatswissenschaft 158(2): $234-255$

Esty BC (1997) Organizational form and risk taking in the savings and loan industry. J Financ Econ 44:25-55

Fang Y, Hasan I, Marton K (2011) Bank efficiency in South Eastern Europe. Econ Transit 19:495-520

Fiordelisi F, Mare D (2014) Competition and financial stability in European cooperative banks. J Int Money Financ 45:1-16

Fu X, Heffernan S (2009) The effects of reform on China's bank structure and performance. J Bank Financ 33(1): 39-52

Ghatak M (2000) Screening by the company you keep: joint liability lending and the peer selection effect. Economic Journal 110(465):601-631

Goodhart C (2004) Some new directions for financial stability. The per Jacobsson lecture. Bank for International Settlements, Basel

Groeneveld H (2011) The value of European cooperative banks for the future financial system', paper presented at the international co-operative Alliance (ICA) global research conference in Mikkely, Finland 
Groeneveld JM, De Vries YB (2009) European co-operative banks: first lessons from the subprime crisis. Working Paper Economic Research Department Rabobank Nederland

Hasan I, Koetter M, Wedow M (2009) Regional growth and finance in Europe: is there a quality effect of bank efficiency? J Bank Financ 33:1446-1453

Hellman T, Mudock K, Stiglitz JE (2000) Liberalization, moral hazard in banking and prudential regulation: are capital controls enough? Am Econ Rev 90(1):147-165

Hesse H, Čihák M (2007) Cooperative banks and financial stability. IMF working paper no. 07/02

Hughes JP, Mester LJ (1998) Bank capitalization and cost: evidence of scale economies in risk management and signaling. Rev Econ Stat 80:314-325

ISTAT, 2005, Sistemi Locali del Lavoro, http://www.istat.it/salastampa/comunicati/non- calendario/ 2005072100/

Keeley M (1990) Deposit insurance, risk and market power in banking. Am Econ Rev 80(5):1183-1200

Klein MA (1971) A theory of the banking firm, journal of money. Credit and Banking 3(2):205-218

Koutsomanoli-Filippaki A, Margaritis D, Staikouras C (2009) Efficiency and productivity growth in the banking industry of central and Eastern Europe. J Bank Financ 33:557-567

Kumbhakar SC, Lovell CA (2000) Stochastic frontier analysis. Cambridge University press, Cambridge, UK. 343

Kumbhakar SC, Lien G, Hardaker JB (2014) Technical efficiency in competing panel data models: a study of Norwegian grain farming. J Prod Anal 41:321-337

Lamm-Tennant J, and LT, Starks (1993) Stocks vs mutual ownership structures: the risk implications. J Bus 66 : 29-46

Liberti JM, Petersen MA (2018) Information: hard and soft. NBER working paper no. 25075

Lind JT, Mehlum H (2010) With or without U? The appropriate test for a U-shaped relationship. Oxf Bull Econ Stat 72(1):109-118

Llewellyn DT (2005) Competition and profitability in European banking: why are British banks profitable? Economic Notes by Banca Monte dei Paschi di Siena SpA 34(3):279-311

Lozano-Vivas A, Pastor J, Pastor JM (2002) An efficiency comparison of European banking systems operating under different environmental conditions. J Prod Anal 18:59-77

Maksimovic V, Unal H (1993) Issue size choice and 'underpricing' in thrift mutual-to-stock conversions. J Financ 48(5):1659-1692

Martin-Oliver A, Ruano S, Salas-Fumas V (2013) Banks' equity capital frictions, capital ratios, and interest rates: evidence from Spanish banks. Int J Cent Bank 9(1):183-225

Martínez-Miera D, Repullo R (2010) Does competition reduce the risk of bank failure? Rev Financ Stud 23: 3638-3664

Margaritis D, Psillaki M (2010) Capital structure, equity ownership and firm performance. J Bank Financ 34(3): 621-632

Mason ES (1939) Price and production policies of large-scale enterprise. Am Econ Rev 29(1):61-74

Masulis RW (1987) Changes in ownership structure: conversions of mutual savings and loans to stock charter. J Financ Econ 18:29-59

Matsuoka T (2013) Sunspot bank runs in competitive versus monopolistic banking systems. Econ Lett 118:247-249

Mester LJ (2017) The nexus of macroprudential supervision, monetary policy, and financial stability. J Financ Stab 30:177-180

Mishkin FS (1999) Financial consolidation: dangers and opportunities. J Bank Financ 23:675-691

O’Hara M (1981) Property rights and the financial firm. J Law Econ 29:317-332

Olszak M, Pipien M, Kowalska I, Roszkowska S (2017) What drives heterogeneity of cyclicality of loan-loss provisions in the EU? J Financ Serv Res 51:55-96

Rajan RG (1994) Why Bank credit policies fluctuate: a theory and some evidence. Q J Econ 109(2):399-441

Restrepo-Tobòn DA, Kumbhakar SC (2017) A new method to decompose profit efficiency: an application to US commercial banks. J Prod Anal 48(2):117-132

Rojas-Suarez L (2002) Rating banks in emerging markets: what credit rating agencies should learn from financial indicators', in R. M. Levich, G. Majnoni and C. M. Reinhart (eds.), Ratings, Rating Agencies and the Global Financial System, the new York University Salomon Center series on financial markets and institutions, Vol 9. Boston, MA: Springer

Schaeck K, Čihák M (2007) Banking competition and capital ratios. IMF working paper 07/216

Schaeck K, Cihák M, Wolfe S (2009) Are more competitive banking systems more stable? Journal of money. Credit and Banking 41(4):711-734

Schrand C, Unal H (1998) Hedging and coordinated risk management: evidence from mutual-to-stock conversions. J Financ 53(3):979-1013

Sealey CW Jr, Lindley J (1997) Inputs, outputs, and a theory of production and cost at depository financial institutions. J Financ 32:1251-1266 
Smith DJ (1984) A theoretic framework for the analysis of credit union decision making. J Financ 39(4):11551168

Stefancic M (2010) Cooperative credit network: advantages and challenges in Italian cooperative credit banks. Euricse working papers, n. 16

Stein JC (2002) Information production and capital allocation: decentralized vs. hierarchical firms. J Financ 57: 1891-1921

Stiglitz J, Weiss A (1981) Credit rationing with imperfect information. Am Econ Rev 71:393-410

Strobel F (2011) Bank insolvency risk and z-score measures with unimodal returns. Appl Econ Lett 18:16831685

Tabak BM, Fazio DM, Cajueiro DC (2012) The relationship between banking market competition and risktaking: do size and capitalization matter? J Bank Financ 36:3366-3381

Tortosa-Ausina E, Grifell-Tatjé E, Armero C, Conesa D (2008) Sensitivity Spanish savings banks. Eur J Oper Res 184:1062-1084

Uhde A, Heimeshoff U (2009) Consolidation in banking and financial stability in Europe: empirical evidence. J Bank Financ 33:1299-1311

Unal H (1997) Regulatory misconceptions in pricing thrift conversions: a closer look at the appraisal process. J Financ Serv Res 11(3):239-254

Verbrugge JA, Goldstein SG (1981) Risk return and managerial objectives: some evidence from the saving and loan industry. J Financ Res 4:45-58

Publisher's Note Springer Nature remains neutral with regard to jurisdictional claims in published maps and institutional affiliations. 